\begin{tabular}{|c|c|}
\hline Volume \& Issues Obtainable at The Women University Multan \\
Annals of Social Sciences and Perspective \\
ISSN: 2707-7063, Volume 2, No.1 June 2021 \\
Journal homepage: http://assap.wum.edu.pk/index.php/ojs
\end{tabular}

\title{
Ethical Issues and Challenges for the Eradication of Polio in Pakistan
}

\section{Syed Waqas Shabir ${ }^{1}$, Dr. Nazia Malik², Dr. Zahira Batool ${ }^{3}$, Murtaza Omer Bashir ${ }^{4}$, Muhammad Rizwan ${ }^{5}$}

${ }^{1}$ Ph.D Scholar (Sociology), Govt. College University Faisalabad.

${ }^{2}$ Assistant Professor Sociology, Govt. College University Faisalabad

${ }^{3}$ Govt. College University Faisalabad.

${ }^{4}$ M.Sc Economics, Deputy Director Admin, Punjab Higher Education Commission, Lahore, Pakistan.

${ }^{5}$ Ph.D Scholar, School of Education Sciences, Nanjing Normal University China.

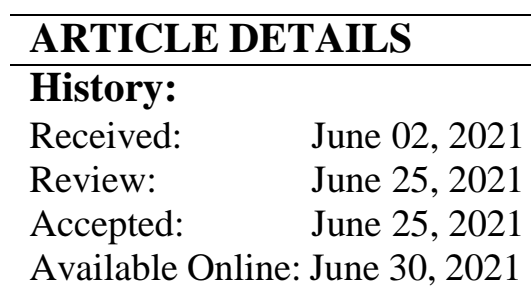

\section{Keywords:}

Ethical issues, Challenges, Polio in Pakistan.

\begin{abstract}
It should be everyone's basic health right to get immunization. Everyone is responsible for this, every individual, every sector, every community, the entire healthcare system and the country. The aim of this paper is to highlight a few issues concerning polio vaccines in Pakistan and suggest some solution to these issues. The developmental plane of this paper is based on literature on polio and public health in Multan, Pakistan perspective. Inclusion criteria base on public health culture, religion and ethical base published review articles. Religious ideas and views affect almost every part of human behavior, including their views and acceptance towards certain healthcare services. For the past few years, the issues regarding polio vaccination have been a highlighted topic in Pakistan. Many steps have been taken by the government to ensure that more people gain immunity against polio. Even so, a large fraction of population appears to be resistant towards polio vaccination and refuses to get vaccinated. The views, thoughts and beliefs of people are considered more of importance tan health concerns. That is why it is very important to understand the context behind these resistances so that proper strategies can be made for dealing with them. Those who are in charge of making policies in Pakistan must pay attention towards the many challenges that are faced during the polio vaccination so that such a plan could be developed while keeps the ethical norms in mind so success could be achieved.
\end{abstract}

(C) 2021 The Authors, Published by WUM. This is an Open Access Article under the Creative Common Attribution Non Commercial 4.0

Corresponding author's email address: syedwaqasshabbir.1149@gmail.com

\section{Introduction}


One of the most gainful public health intercessions is immunization, which has had the most positive effect on decrease in various diseases and death of children under the age of five years old. Immunization should be perceived as the basic health right of every human and thus, this makes everyone equally responsible for making it widespread whether it is the public or the government. Research has given proof that vaccination brings about a great deal of reduction in diseases but still, the issues behind not having 100\% immunization calls for better understanding and research of the issue. Better immunization significantly lowers the chances of contracting diseases, disabilities or facing death. Polio is seen as a disease which paralysis a part of or the entire body, but eradication of polio has proven to be a challenge worldwide. If due to any reason someone doesn't receive the vaccination, then if enough people around them are vaccinated, then because of 'herd immunity', that person is protected from the diseases if disabilities. It has been shown that the attitude and behavior a community shows towards vaccination and immunization has a great influence from religious views and beliefs. Religious beliefs and practices play the roles of guides for many different practices, including the practices related to health-care. Constant efforts are being made by health-care officers and researchers to incorporate religious and cultural elements in health care practices so that these practices can be made more acceptable worldwide. A critical review is taken as the basis for this paper, focusing on the religious and ethical issues involving the polio vaccination in Multan, Pakistan and suggestion have been given for how to deal with these issues in an effective manner.

\section{Methodology}

To search for relevant literature internet was used, most relevant literature was highlighted. The inclusion criteria are articles related to polio in Pakistan. Another inclusion criteria was related to culture and public health, religion focus literature. Culture, religion and norms focus literature helps to understand psychology behind using polio vaccine.

\section{Discussion}

Today, one of the main reasons the polio vaccination has not been accepted by the entire population of Pakistan is the uncertainty as well as the disagreement of people. Various NGOs as well as the government has been hesitant to give civilized assistance to the refugees and expatriates unless they take the polio vaccine for their child, which has caused a layer of doubt and mistrust in people. A question that arises from this is that does the state have the right to force such conditions on refugees when the serious health problems, which can be prevented with vaccine, are having serious health impacts on the locals, the health-care workers and other workforces in Pakistan. These are just excusing to decide when the ethical deliberations essential for the general public health and well-being (eradication and prevention of harms, providing benefits etc.) can be considered as a priority over other issues and goals, if ever there is such a need to do so during certain public health activities. These conditions are seen as proportionality of the health-related actions (general well-being of public is a bigger priority than other ethical issues), importance of the actions, the efficiency of those actions, and the lowest possible extent to which the actions violate the ethical considerations as well as the extent to which public can openly and easily justify those actions. Given that immunization can be seen as a public health program, it is said that it is a part of the moral structure. In addition to this, vaccination not only has a positive effect on the person being vaccinated but also has a positive effect on the health of the entire community, it can be said that people not being vaccinated or not choosing to take the vaccine are posing a direct threat to their community. 
The issues such as high rates of illiteracy, isolated populations, religious beliefs and views and false beliefs such as polio vaccine contains pig fat, it can cause sterility or the vaccines are not of good standard etc. have not been addresses on a large scale. In addition to this, another issue is that there is no proper planning from the government about the eradication of polio on a large scale as it focuses only on vaccinating children multiple times a year. This can cause even further mistrust and doubt in the public. This makes it necessary that a fair and must share of resources are given to healthcare systems, while keeping in mind the needs and beliefs of people.

Moreover, the lack of proper strategies and poor management by the authorities have also proven to be a great hurdle, where the authorities responsible for the required resources couldn't agree with each other, neither were they fined for teaming up with the religious leaders for campaigning the vaccine. If we want to achieve a worldwide success under the polio eradication initiative going on worldwide, it is important that we do not ignore the social and cultural norms of Pakistan.

\section{The Pakistani Perspective}

The health care system of Pakistan has to undergo difficult geographical challenges ranging from the ice-cold Himalayan glaciers to the burning and rough terrains in Balochistan, which causes poor health management and delivery. Lately, immunization for polio eradication has become a much talked about topic in Pakistan. Only three countries in the world still deals with polio and Pakistan is one of them. The most resistance that polio workers face are from the provinces of Khyber Pakhtunkhwa and Balochistan. When in 2014, India became polio free on one hand, on the other hand , 306 polio cases were reported in Pakistan, which makes up $80 \%$ of all cases of polio worldwide. 53 more cases were found in 2015. Almost $96 \%$ of all polio cases in Pakistan were from Khyber Pakhtunkhwa.

Efforts of polio eradication worldwide are highly dependent of the capacity of Pakistan to deal with the various hurdles to immunization such as religious views, beliefs, norms, political issues, socio-economic issues, improper coverage from vaccine, improper health infrastructure and issues in those areas of the country where polio still exists. In addition to this, many studies have shown that social, cultural and religious factors play a vital role in the parents' disagreement to get their child immunized, which proves to be a great issue for healthcare workers. One of the most common religious belief that causes issues in vaccination is that a disease in the body is by Allah's will. Even today, some areas of Pakistan still deal with transmission of polio from one person to another. This constant resistance to polio vaccine is complex and complicated. It has put nearly 25,000 children in Khyber Pakhtunkhwa at risk. This is because of many reasons such as resistance, inability to reach certain areas, security issues, not enough female vaccinators etc.

For now, many projects are being carried out in Pakistan by the National Program of Immunization to raise awareness about diseases and improve the vaccination rates in the country. Such projects carry out activities like discussions with the religious clergies [20], making information handling systems, enhancing the cold chain, focusing on field work done to act towards a more research-based approach, public awareness programs and the biggest project is increasing their reach to different houses through female workers alongside appropriate security due to unstable border conditions at some areas.

Some studies also show poor education and awareness regarding the vaccines to be a major factor contributing towards a strong attitude against vaccination. As such, programs should 
also keep the local culture in mind when going about the mission of vaccinating for polio. Understanding how religion and culture of a place affects its people's values would prove greatly beneficial for the cause. This brings up a pondering query: the question regarding the ethicality of providing vaccination to a mass uneducated to have a proper understanding of its use or an understanding required for a meaningful decision of yes or no. Similarly, the ethicality of the people is also put into question regarding their actions of rejecting the vaccine, a protection for their children against a greatly immobilizing disease. Though the question of ethnicity is a profound one, it is not at all new.

Letting your child fall prey to a harmful disease disabling them for their whole life by choosing to not administrate the vaccine and creating a situation, which would have been easily avoidable, is in no way an ethical decision. Nevertheless, the resistance against vaccination is not an issue limited to Pakistan. This resistance due to peoples' religion or tradition is an issue widely documented. As a result, many strategies and ideas have been formulated to deal with this issue. As an example, social mobilization acts to strengthen and enables those who take benefit from a scheme to attain control of it. Likewise, pragmatic social mobilization occurs through including leaders of different communities. Even this method does not work in situations where the people actively show resistance to medical help, usually arising from religious or traditional beliefs. This issue can more easily be dealt with. Approaching the lowest levels of organizations might be another method to reach people. The method proved successful in the past when water and sanitation and healthcare for children was introduced, but has been proven ineffective in polio administration in areas showing active opposition to the immunization.

A solution for this may be a mixture of the aforementioned approaches where the local governments are made a part of the polio program all the while approaching the notable ones in each community. This may prove effective in dealing with the situation in Pakistan. Here, religious beliefs and traditional methods are more revered over scientific advancements. The 2016 Pakistan was in the bottom ten of the prosperity index among 142 countries. This also puts Pakistan at 147 in the global developmental index, something that has remained unchanged for the past five years . Even if the concept of a global mission to remove polio is a program to vast for most people to understand, this resistance against it proves as one of the strongest factors which keep Pakistan low in the developmental index. The aid of the educational ministers for this purpose is integral. It is important that a parent must be provided with proper maternal information in due time and as such, immunization is also an integral part of that education which in to be provided to the parents to prevent any disabilities in the child. Researches show women be able to play an integral part in shaping the attitudes of the families regarding the polio vaccination program, as they are the first house caretaker alongside being the one most concerned with the child. This leads to the female vaccinators being able to more easily access the women of the house and approach them regarding their child's immunization. Nevertheless, the patriarchy in Pakistan may make it so that approaching the men (the head of the house) may prove more effective than the women. Places where women are given less control over the child's health tend to show lower polio immunization rates. Thus, the males of the house are also to be informed of the issues.

Furthermore, an important factor is the conspiracy theory that the polio vaccines are an elaborate scheme against the people of Pakistan to harm their children. This is something that needs to be eradicated from the core through public educational programs. An issue like this can easily be dealt with by having famous and well-known public figures and celebrities to 
show support to the vaccination program. Changing our behavior about child immunization programs to gain back people's trusts, dealing with the causes of resistance against immunization and emotionally approaching the people for vaccination can be effective steps in improving the vaccination percentage.

\section{Conclusions}

Immunization against polio in Pakistan is a complicated issue facing its own forms of ethical, social and cultural issues. The more the administration takes a part in the polio immunization program, the more it becomes possible for the it to become a widely accepted program in Pakistan and the easier it would become for eradication of polio to occur. As the polio eradication projects in Pakistan face a multitude of challenges in their efforts, a prime opportunity arises to utilize a number of strategies for better success. These strategies must be so established that they do not interfere with the cultural or religious beliefs of the people. They must also be made to be possible to be implemented by the government. Keeping privacy, self-autonomy, ethicality, and integrity can prove greatly helpful in establishing a countrywide approach to polio immunization where the masses may even show voluntary participation.

\section{References}

Ahmad SO, Yousuf F, Bux AS, Abu-Zaid A. Pakistan: the final frontier for global polio eradication. J Epidemiol Community Health. 2016;70(2):109-10.

Ahmed QA, Nishtar S, Memish ZA. Poliomyelitis in Pakistan: time for the Muslim world to step in. Lancet. 2013;381(9877):1521-3.

Alexander JP, Zubair M, Khan M, Abid N, Durry E. Progress and peril: poliomyelitis eradication efforts in Pakistan, 1994-2013. J Infect Dis. 2014; 210 suppl 1:S152-61.

Aylward B, Tangermann R. The global polio eradication initiative: lessons learned and prospects for success. Vaccine. 2011;29:D80-5.

Bandyopadhyay AS, Garon J, Seib K, Orenstein WA. Polio vaccination: past, present and future. Future Microbiol. 2015;10(5):791-808.

Bencskó G, Ferenci T. Effective case/infection ratio of poliomyelitis in vaccinated populations. Epidemiol Infect. 2016;144(9):1933.

Bhutta ZA. Conflict and polio: winning the polio wars. JAMA. 2013;310(9):905-6.

Bhutta ZA. Infectious disease: Polio eradication hinges on child health in Pakistan. Nature. 2014;511(7509):285.

Bhutta ZA. The last mile in global poliomyelitis eradication. Lancet. 2011; 378(9791):54952.

Centers for Disease Control and Prevention (CDC). Progress toward poliomyelitis eradication-Pakistan, 1994-1998. MMWR Morb Mortal Wkly Rep. 1999;48(6):121.

Centers for Disease Control and Prevention (CDC). Progress toward poliomyelitis eradication-Pakistan and Afghanistan, January 2000-April 2002. MMWR Morb Mortal Wkly Rep. 2002;51(24):521.

Closser S. Chasing polio in Pakistan: why the world's largest public health initiative may fail. Nashville: Vanderbilt University Press; 2010.

Dawn. Imran launches Sehat Ka Ittehad for KP, Fata. 2015. [online] Available at: http://www.dawn.com/news/1163552. Accessed 16 Dec 2015.

Dunn G, Klapsa D, Wilton T, Stone L, Minor PD, Martin J. Twenty-eight years of poliovirus replication in an immunodeficient individual: Impact on the Global Polio Eradication Initiative. PLoS Pathog. 2015;11(8):e1005114. 
Feldbaum H, Lee K, Michaud J. Global health and foreign policy. Epidemiol Rev. 2010;32(1):82-92.

Garon JR, Orenstein WA. Overcoming barriers to polio eradication in conflict areas. Lancet Infect Dis. 2015;15(10):1122-4.

Global Polio Eradication Initiative. Global Polio Eradication Initiative $>$ Data and monitoring $>$ Polio this week > Wild poliovirus list. 2016. [online] Available at: http://www.polioeradication.org/dataandmonitoring/poliothisweek/wildpolioviruslist. aspx. Accessed 22 May 2016.

Global Polio Eradication Initiative. Wild Poliovirus List 2010-2015. 2015. [online] Available at:

http://www.polioeradication.org/Portals/0/Document/Data\&Monitoring/Wild_poliovir us_list_2010-2015_29DEC.pdf. Accessed 30Dec 2015

Hagan JE, Wassilak SG, Craig AS, Tangermann RH, Diop OM, Burns CC, Quddus A. Progress toward polio eradication-worldwide, 2014-2015. MMWR Morb Mortal Wkly Rep. 2015;64(19):527-31.

Hasan Q, Bosan AH, Bile KM. A review of EPI progress in Pakistan towards achieving coverage targets: present situation and the way forward. East Mediterr Health $\mathrm{J}$. 2015;16:S31-8.

Hussain SA, Menezes RG, Nagaraja SB. Parents in Pakistan arrested for polio vaccine refusal: a necessary step? Lancet. 2015;385(9977):1509.

Hussain SA, Nagaraja SB, Menezes RG. Military intervention: The last option for polio eradication in Pakistan? J Infect Public Health. 2015;8(5):508-9.

International Ulama Conference on Polio Eradication, Islamabad, Pakistan. Islamabad Declaration/Fatwa. 2014. [online] Available at: http://www.endpolio.com.pk/beta/images/reports/English-Declaration.pdf Accessed 20 Mar 2016.

Iqbal MS, Iqbal MW, Iqbal MZ, Bahari MB. Knowledge, Attitude and Perception of Polio (Poliomyelitis) among General Public in Pakistan. Value Health. 2015;18(7):A591.

Kaufmann JR, Feldbaum H. Diplomacy and the polio immunization boycott in Northern Nigeria. Health Aff. 2009;28(4):1091-101.

Keja K, Chan C, Hayden G, Henderson RH. Expanded programme on immunization. World Health Stat Q. 1987;41(2):59-63.

Kevany S. Diplomatic advantages and threats in global health program selection, design, delivery and implementation: development and application of the Kevany Riposte. Glob Health. 2015;11(1):1.

Kevany S. Global health diplomacy, 'smart power', and the new world order. Glob Public Health. 2014;9(7):787-807.

Kevany S. Global health engagement in diplomacy, intelligence and counterterrorism: a system of standards. J Policing, Intell Count Terror. 2016;11(1):84-92.

Kevany S. James Bond and Global Health Diplomacy. Int J Health Policy Manag. 2015;4(12):831.

Khan MU, Ahmad A, Aqeel T, Salman S, Ibrahim Q, Idrees J, Khan MU. Knowledge, attitudes and perceptions towards polio immunization among residents of two highly affected regions of Pakistan. BMC Public Health. 2015;15(1):1.

Khan T, Qazi J. Hurdles to the global antipolio campaign in Pakistan: an outline of the current status and future prospects to achieve a polio free world. J Epidemiol Community Health. 2013;67(8):696-702.

Khan TM, Chiau LM. Polio vaccination in Pakistan: by force or by volition? Lancet. 2015;386(10005):1733. 
Khan TM, Sahibzada MUK. Challenges to health workers and their opinions about parents' refusal of oral polio vaccination in the Khyber Pakhtoon Khawa (KPK) province, Pakistan. Vaccine. 2016;34(18):2074-81.

Khowaja AR, Khan SA, Nizam N, Omer SB, Zaidi A. Parental perceptions surrounding polio and self-reported non-participation in polio supplementary immunization activities in Karachi, Pakistan: a mixed methods study. Bull World Health Organ. 2012;90(11):822-30.

Kopel E, Kaliner E, Grotto I. Lessons from a public health emergency-importation of wild poliovirus to Israel. N Engl J Med. 2014;371(11):981-3.

Larson HJ, Ghinai I. Lessons from polio eradication. Nature. 2011; 473(7348):446-7.

Mangrio NK, Alam MM, Shaikh BT. Is expanded programme on Immunization doing enough? Viewpoint of health workers and managers in Sindh, Pakistan. J Pak Med Assoc. 2008;58(2):64.

Mushtaq A, Mehmood S, Rehman MAU, Younas A, Rehman MSU, Malik MF, Hyder MZ. Polio in Pakistan: Social constraints and travel implications. Travel Med Infect Dis. 2015;13(5):360-6.

National Task Force For Polio Eradication. National Emergency Action Plan For Polio Eradication. 2015. [online] Available at: http://www.polioeradication.org/Portals/0/Document/InfectedCountries/Pakistan/2015 -16_NEAP_Pakistan.pdf. Accessed 28 Apr 2016.

Nishtar S. Pakistan, politics and polio. Bull World Health Organ. 2010;88(2): 159-60.

Obregón R, Chitnis K, Morry C, Feek W, Bates J, Galway M, Ogden E. Achieving polio eradication: a review of health communication evidence and lessons learned in India and Pakistan. Bull World Health Organ. 2009; 87(8):624-30.

O'Reilly KM, Durry E, ul Islam O, Quddus A, Mir TP, Tangermann RH, Aylward RB, Grassly NC. The effect of mass immunisation campaigns and new oral poliovirus vaccines on the incidence of poliomyelitis in Pakistan and Afghanistan, 2001-11: a retrospective analysis. Lancet. 2012;380(9840):491-8.

Orenstein WA, Byington CL, Maldonado YA, Barnett ED, Davies HD, Edwards KM, Jackson MA, Murray DL, Rathore MH, Sawyer MH, Schutze GE. Eradicating polio: how the world's pediatricians can help stop this crippling illness forever. Pediatrics. 2015;135(1):196-202.

Owais A, Khowaja AR, Ali SA, Zaidi AK. Pakistan's expanded programme on immunization: An overview in the context of polio eradication and strategies for improving coverage. Vaccine. 2013;31(33):3313-9.

Patriarca PA, Wright PF, John TJ. Factors affecting the immunogenicity of oral poliovirus vaccine in developing countries: review. Rev Infect Dis. 1991; 13(5):926-39.

Rubenstein LS. Global health and security in the age of counterterrorism. J R Soc Med. 2015;108(2):49-52.

Salk D. Eradication of poliomyelitis in the United States. II. Experience with killed poliovirus vaccine. Rev Infect Dis. 1980;2(2):243-57.

Siddiqui NT, Owais A, Agha A, Karim MS, Zaidi AK. Ethnic disparities in routine immunization coverage a reason for persistent poliovirus circulation in Karachi, Pakistan? Asia Pac J Public Health. 2013. doi:10.1177/1010539513475648.

SteelFisher GK, Blendon RJ, Guirguis S, Brulé A, Lasala-Blanco N, Coleman M, Petit V, Ahmed M, Mataruse N, Corkum M, Nisar M. Threats to polio eradication in highconflict areas in Pakistan and Nigeria: a polling study of caregivers of children younger than 5 years. Lancet Infect Dis. 2015;15(10): 1183-92. 
Tangermann RH, Hull HF, Jafari H, Nkowane B, Everts H, Aylward RB. Eradication of poliomyelitis in countries affected by conflict. Bull World Health Organ. 2000;78(3):330-8.

Tomkins A, Duff J, Fitzgibbon A, Karam A, Mills EJ, Munnings K, Smith S, Seshadri SR, Steinberg A, Vitillo R, Yugi P. Controversies in faith and health care. Lancet. 2015;386(10005):1776-85.

United Nations Department of Economic and Social Affairs. World Population Prospects: The 2015 Revision. 2015. [online] Available at: http://esa.un.org/unpd/wpp/DataQuery/. Accessed 15 Dec 2015.

Walsh, D. Taliban Block Polio Vaccinations in Pakistan. [online] The New York Times. 2012. Available at: http://www.nytimes.com/2012/06/19/world/asia/taliban-blockvaccinations-in-pakistan.html. Accessed 16 Dec 2015.

Weekly Epidemiological Record. Polio vaccines: WHO position paper, January 2014. Geneva: World Health Organization; 2014.

World Health Organization. Polio Eradication and Endgame Strategic Plan (2013-2018), Global Polio Eradication Initiative, working draft, 23. 2013. p. 1-99.

World Health Organization. WHO | Poliomyelitis (Polio). 2015. [online] Available at: http://www.who.int/ith/diseases/polio/en/. Accessed 12 Dec 2015.

World Health Organization. WHO statement on the second meeting of the International Health Regulations Emergency Committee concerning the international spread of wild poliovirus. Saudi Med J. 2014;35(8):920-2. 